\title{
EDITORIAL
}

\section{NURSES ARE PEOPLE TOO}

As 1995 draws to a close it is timcous to examine some issues pertinent to the nursing profession; with only four years to the next century we should be taking stock and putting in place professional care/practice and research agendas. In South Africa, these have been glaring by their absence which to some extent may be explained by the current pressures, on society and a profession characterized by women who have typically accepted a subservient role.

The South African Nursing Council publishes annual statistics enumerating categories and distribution of nurses. Behind these statistics are the people who are integral a very complex society. For this reason, projects and research which examine or enhance the interface of nurses and clients contributes to the benefit of all people.

The patients' charter being developed by the National Progressive Primary Health Care Network includes rights and obligations of both clients and providers and invites comments from both. Some local research carried out is relevant to these issues. For example, Zimu (1989) examined professional nurses' experiences of carrying out their work during community violence. A qualitative study of the life histories of professional nurses working and living in rural areas showed that a third of the 100 subjects reached registered nurse status via assistant and enrolled nursing. Almost all participated actively in socially important groups and projects in addition to working full time, all had dependants of various kinds, and when the opportunity presented they made huge personal sacrifices to embark on continuing professional education (Kortenbout 1994). Further data about the working and personal lives of nurses would inform "The government" and public that it is necessary to address issues such as the strikes which have been publicized this year. Taylor (1992: 1042) explored the nurse as a person and said "The possibility is raised that a re-conceptualization of the nurse could describe the nurse, not only as a professional helper, but also as a human whose effectiveness is enhanced through a sense of shared humanity with patients".

Castledine (1992) listed rights for nurses such as fair pay, equal opportunities, participation in policy-making, social and political action on behalf of nursing and health care and good working conditions.

The last point should be ensured as our Occupational Heal th and Safety Act applies to health care settings but various issues are still not clear eg. universal precautions should be well and truly entrenched yet many nurses have great difficulty in accessing even one pair of gloves.

The essential humanness of all people is limited by categorizing nurses and patients or clients into discrete groups (Taylor 1992). The interrelatedness of nurses and people in a wider context than merely a health care setting cannot be ignored. The trends and issues that impact on nursing and on which nursing acts also supports this contention. The shift of nurses being seen as resources for institutions and other disciplines to that of nurses seen as resources for people (Moore 1990) is neither well developed nor well understood locally.

The following trends are likely to continue beyond 2000 and illustrate that nurses need to be resourceful to people yet will experience simultaneously the same issues as those affecting all people

Some of these trends are

Client advocacy at both individual and aggregate lives with potential for conflict and even personal danger as well as the pursuance of equity.
Multifaceted health and illness management in which the nurse not only collaborates with other sectors and disciplines but also interacts with community based workers and alternative health care providers ensuring client referrals in both direction.

Understanding and promoting good hum an relationships (and by cultural sensitivity) will continue to be important.

Telematics, in which new information technologies, new combinations of technologies and communication systems are featured

Quality care and access to it are issues that have already been taken up by consumer groups and nurses particularly could be placed under immense pressure.

Economic Restraints are unlikely to be eliminated and creative responses must be devised by nurses. Productivity related to costs is likely to be examined and the specific contribution of nursing will need to be identified. For this reason the ICN projoct on classification nomenclature is important. Furthermore this aspect of productivity could be complex as the consumer and quality aspects determine that simple counting of numbers of immunizations, dressings and so on, will be inadequate.

Social organization/mobilization is already extensive and likely to continue with lobbying to press for different ways of health care provision. Nurses will have to keep track of these and identify implications.

Policy-making - opportunities for input have already been given to nurses, who were frequently unable to respond. Nurses will have to be better informed in general and display negotiation skills

Nursing, if it is to make a significant contribution to the wellbeing of all must take on a "pathfinder or trend setter role and engage in anticipatory nursing" ( $\operatorname{van}$ Masnen 1990:992). Direction from other disciplines or simply reacting to public and service pressures is no longer good enough for that profession identified to play the major part in reconstructing and developing our society. Accepting the humanness of nurses is the start of their personal reconstruction and development.

\section{REFERENCES}

Castled ine G. (1992) : Nurses have rights too. Journal of Advanced Nursing 17, 1042-1049

Kortenbout H. (1994) : Personal and Professional development of Rural Nurses in KwaZulu Natal (unpublished)

Moore S. (1990) : Thoughts on the discipline of nursing as we approach the year 2000. Joumal of Advanced Nuraing 15, 825-828

Taylor, B.J. (1992) : From Helper to Human: a re-conceptualization of the nurse as person. Jourmal of Advanced Nurning 17, 1042-1049

Van Mtanen. H.M. (1990): Nursing in transition: an analysis of the state of the an in relation to the conditions of practioe and society's expecturions Joumal of Advanced Nuraing 15,914.924

Zimu. T.E (1991): Effect of violence on bleck professional nurses working in peri-urban areas. Durban University of Nasal (unpublished Masters thesis)

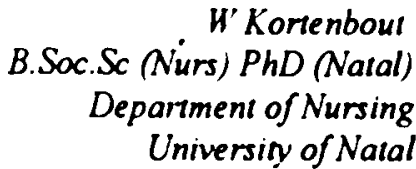

